\title{
Population size and structure of the Nile crocodile Crocodylus niloticus in the lower Zambezi valley
}

\author{
Kevin M. Wallace, Alison J. Leslie, Tim Coulson and Audrey S. Wallace
}

\begin{abstract}
Concern has been raised about the lack of population data for the Nile crocodile Crocodylus niloticus in the lower/middle Zambezi valley. This area is important for conservation as well as being a source of crocodile eggs and adults for the ranching industry. Two spotlight surveys, in 2006 and 2009, were used to estimate population size, structure and trends. A stage-structured matrix model was parameterized from existing literature and the expected predictions were compared to those observed. The survey data suggests a population increase since 2006. Crocodile density was greatest $\left(3.1 \mathrm{~km}^{-1}\right)$ in the areas of increased wildlife and habitat protection and lowest $\left(1.4 \mathrm{~km}^{-1}\right)$ in areas of increased human presence. The predicted population stage structure differed to that observed, suggestive of a population not at equilibrium. Data on offtakes of crocodile eggs and adults would be useful for examining why this is the case. Continued monitoring of the wild population is necessary, to evaluate the trend of an increasing crocodile population, and additional demographic data for modelling purposes would be desirable.
\end{abstract}

Keywords Conservation, Crocodylus niloticus, management, matrix model, Nile crocodile, spotlight survey, Zambezi valley

This paper contains supplementary material that can be found online at http://journals.cambridge.org

\section{Introduction}

C rocodilians fulfil an essential ecosystem role (Mazzotti et al., 2009) and have inherent commercial value for both the leather industry (Hutton et al., 2002) and tourism (Telleria et al., 2008). Overexploitation can cause population crashes, leaving some populations potentially vulnerable (Bishop et al., 2009) or critically threatened (Ballouard et al., 2010). Conservation efforts have allowed some populations to recover (Webb et al., 2000). Sustainable utilization of crocodilians is possible and some species show

Kevin M. Wallace (Corresponding author) Tim Coulson and Audrey S. WALLACE Imperial College London, Division of Ecology and Evolution, Silwood Park, Ascot, Berkshire, SL5 7PY, UK.

E-mail kmwallace03@hotmail.com

ALISON J. LESLIE Department of Conservation Ecology and Entomology, Faculty of Agrisciences, University of Stellenbosch, South Africa

Received 16 June 2011. Revision requested 17 November 2011.

Accepted 24 November 2011. resilience to harvesting (Velasco et al., 2003). Habitat loss (Thorbjarnarson et al., 2002) and human-crocodile conflict (McGregor, 2005) are also exerting pressure on crocodilians. The multitude of threats is a serious concern and monitoring of populations is a critical process in the management of any species. Despite this, of the many surveys of crocodilians throughout Africa only a small percentage facilitate estimation of population trends because of temporal, spatial and methodological inconsistencies (Lainez, 2008), and therefore the status of crocodiles in Africa is not well-known.

The Nile crocodile Crocodylus niloticus in Zambia and Zimbabwe is categorized as Lower Risk/least concern on the IUCN Red List (Crocodile Specialist Group, 1996). It is listed on Appendix II of CITES, which denotes a species not necessarily threatened with extinction but one that may become so unless trade is closely controlled. The wild crocodile population in Zambia and Zimbabwe remains an important resource for the crocodile farming and ranching industry through the harvesting of eggs and adult breeding stock. It has been noted that continuation of this practice alongside a lack of baseline scientific data may have a detrimental effect on the wild population (Siamudaala et al., 2004).

If the size and structure of the wild population can be estimated, this information can be used to compare the results with a theoretical model, as this can provide insight into whether the study population is typical of other populations of the same species. Such insight can help inform management plans. Population models have been developed for numerous crocodilian species (Smith \& Webb, 1985; Craig et al., 1992; Tucker, 2001; Gallegos et al., 2008). One of the simplest models used to predict growth rates and stable stage structure is a discrete stage-structured model (Caswell, 2001), which facilitates predictions of the growth rate, stage structure, reproductive input and sensitivity analysis (Caswell, 2001). This demographic analysis can offer valuable information for the management of species. The models are used to simulate the impact of intervention scenarios, such as the effect of harvesting animals of a certain size or increasing the survival of individuals. Analyses conclude that perturbations to the survival of the mature breeding size class (e.g. by trophy hunting) have a greater effect on population growth than that of perturbations at the egg stage or smaller size classes (Craig et al., 1992; Tucker, 2001). This is useful as conservation funds are often limited and specifically targeting such funds at a part of the life cycle that results 
in the desired outcome in the most cost-effective way is important.

Nocturnal spotlight surveys are the most commonly used technique for evaluating crocodile populations and trends over time. Difficulties encountered during such surveys can range from physical access to areas, and technical bias such as observer skill and boat speed (Cherkiss et al., 2006), to environmental variables such as water level and temperature (Hutton \& Woolhouse, 1989). The technique can underestimate populations because of these difficulties and because of the cryptic nature of crocodiles (Bayliss et al., 1986; Hutton \& Woolhouse, 1989). Therefore the results of spotlight surveys are often interpreted as a population index. The real population size is often unknown as complete counts of an entire study site are rarely possible. Population indices are estimated from incomplete counts that may incorporate correction factors (Hutton \& Woolhouse, 1989; Fergusson, 2006). Repeated standardized spotlight surveys are the most common form of population monitoring for crocodiles (Seijas \& Chavez, 2000). As long as a bias is consistent, the population index will remain relative to the true population count and inferences can be made from the population index in subsequent years of surveys to establish population trends. The estimates should be interpreted carefully but are still the primary indicator of population status for crocodilians.

This study is a follow-up survey to that of Fergusson (2006). Our objectives were to (1) compare our 2009 spotlight survey with that of 2006, (2) parameterize a stagestructured matrix model for C. niloticus, and (3) compare the predicted population structure from the model to that observed in the wild. We discuss the results in terms of management recommendations.

\section{Study area}

The stretch of the Zambezi River between Kariba dam and Cahora Bassa has been termed both the lower and middle Zambezi, hereafter we refer to this area as the lower Zambezi. The area has a distinct wet season during November-April, followed by a cool dry season (MayJuly) and a hot dry season (August-October). The lower Zambezi study area (Fig. 1) extends from Nyamumba at the western extreme to the confluence of the Zambezi/Luangwa River (Kanyemba) in the east and is c. $270 \mathrm{~km}$ long, following the main Zambezi channel. The lower Zambezi River is relatively shallow and wide with occasional islands and it meanders between floodplains on either side. The River is navigable although sandbars can restrict travel by boat in certain areas. The Kafue and Luangwa Rivers are the only two major tributaries that enter the Zambezi. Because of its size and lack of navigability the Luangwa River was not surveyed. The lower reaches of the Kafue River were surveyed up to $20 \mathrm{~km}$ from the confluence, where shallow rapids prevented further upstream travel.

There are four levels of wildlife/habitat protection: open areas, game management areas, safari areas and protected areas. Open areas allow human settlement, development and agriculture. Game management areas allow settlement and agriculture but also act as a buffer zone for protected areas. Safari areas do not allow human settlement or agriculture but permit wildlife hunting and harvesting quotas (as do open areas and game management areas). The two protected areas (Lower Zambezi National Park and Mana Pools National Park) have the highest levels of wildlife/habitat protection and are no-take zones for wildlife. The human population is highest along the Zambian riverbank, being most concentrated in the Chiawa Game Management Area and the Siavunga Open Area, although there are numerous tourist and hunting lodges along the entire length of the Zambezi River in both Zambia and Zimbabwe. To maintain consistency with the 2006 survey the study site was separated into two main sections, the eastern section, Kanyemba to Ruckomechi (the upstream border of Mana Pools), which includes the National Parks, and the western section, Ruckomechi to Nyamumba, which has a lower overall level of wildlife/habitat protection and a higher level of human population and agricultural development.

\section{Methods}

Research protocols were similar to that of Fergusson's (2006) survey, to facilitate comparisons. A nocturnal spotlight survey was used to census the population from a 5-m swamp cruiser boat powered by a 60-hp outboard motor during September, the same month as the 2006 spotlight survey. The survey was timed to coincide with the new moon phase (the darkest period of the month). The weather was cloudless with calm river conditions, good visibility and the mean air temperature $\left(27.3 \pm \mathrm{SE} 0.1^{\circ} \mathrm{C}\right)$ exceeded that of the temperature $\left(24.7 \pm \mathrm{SE} 0.1^{\circ} \mathrm{C}\right)$, providing optimal spotlighting conditions (Hutton \& Woolhouse, 1989). The water level was low prior to the wet season (NovemberApril), when the water level peaks. The same experienced spotlighter and coxswain were used for each night shift during the survey.

Only one survey boat and crew were available and therefore only one bank could be surveyed at a time because of the width of the river (c. $500 \mathrm{~m}$ ). The Zimbabwe riverbank was surveyed first (4 days), then the Zambia riverbank ( 5 days; the additional day being used to survey the lower reaches of the Kafue River). Each local region of the study site constituted a consecutive night survey. The main bank was followed at a distance of 5-10 $\mathrm{m}$ from the shoreline and, where possible, islands were circumnavigated. Crocodiles were located by eye-shine using a 500,000 candle-power 


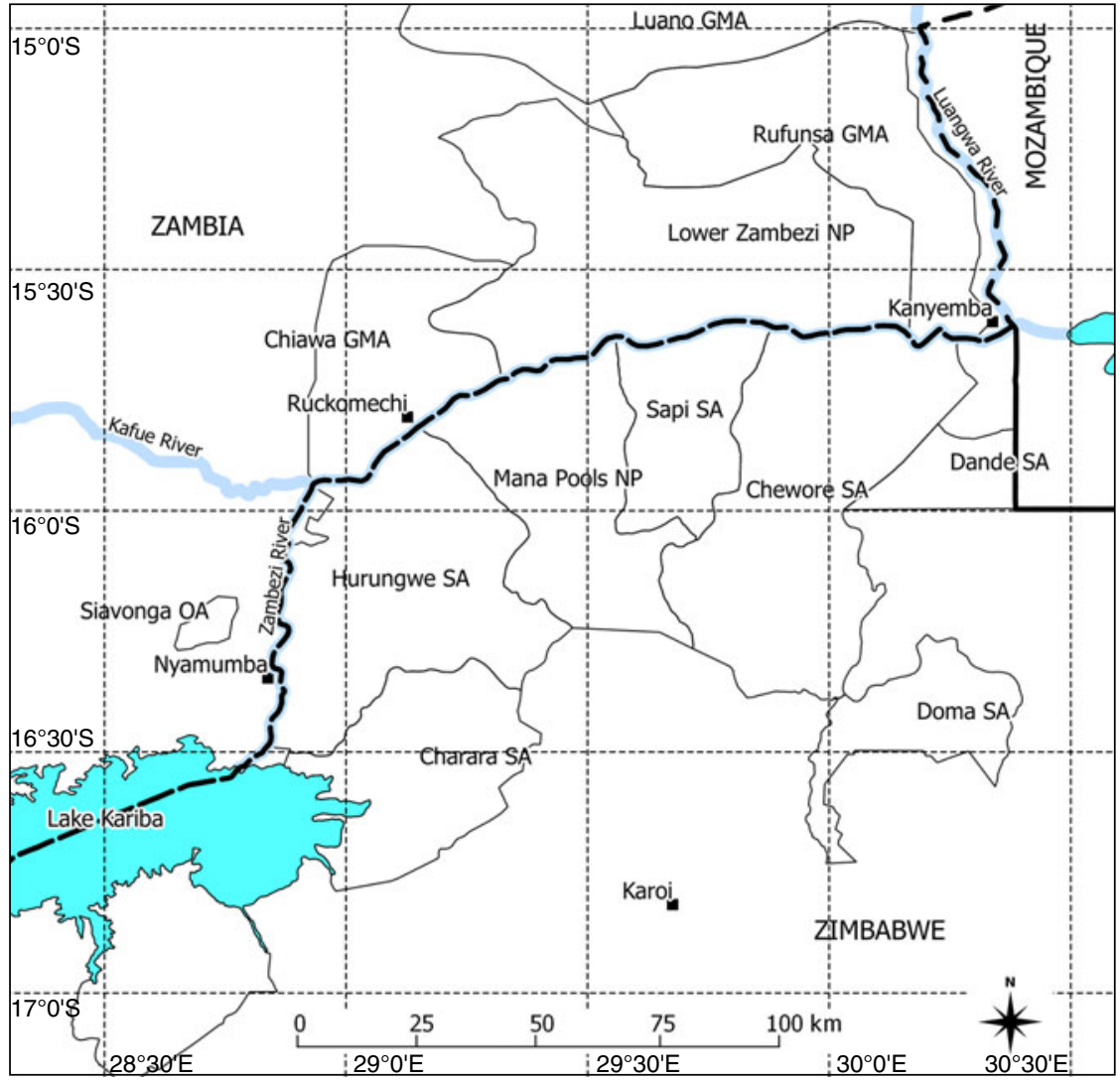

FIG. 1 The lower Zambezi study site, with the main rivers (Zambezi, Kafue and Luangwa). The Zambezi River forms the international border between Zambia and Zimbabwe. OA, Open Area; GMA, Game Management Area; SA, Safari Area. spotlight. The survey was undertaken travelling upstream $\left(8-12 \mathrm{~km} \mathrm{~h}^{-1}\right)$; the spotlight beam was traversed through an arc of $180^{\circ}$ illuminating the riverbank and main channel. The upstream direction was chosen for safety reasons and boat control. When eye-shine was observed, the crocodile was approached as closely as possible to estimate its total length. If the entire animal could not be seen estimation of total length was based on the head length, exposed above the water line. This allowed extrapolation to total length $(7 \times$ the length of the head; Hutton, 1987); this relationship was confirmed by morphometric measurements that we made during a capture survey (mean 7.1 \pm SE $0.11, \mathrm{n}=550$ ). When a crocodile submerged before the observer could estimate the size, the sighting was recorded as eyes-only. A global positioning system (GPS) was used to map locations and routes. Crocodiles were separated into four size classes following Fergusson's (2006) study: hatchlings and yearlings (total length $<0.5 \mathrm{~m}$ ); juveniles (total length $0.5-1.0 \mathrm{~m}$ ); subadults (total length $1.0-2.5 \mathrm{~m}$ ); adults (total length $>2.5 \mathrm{~m})$.

\section{Repeated area surveys}

Between September 2007 and November 2009 other spotlight counts were conducted as part of a capture study using the spotlight technique described above and accepted crocodile capture methods (Webb \& Messel, 1977). These are hereafter referred to as the 'capture surveys'. Crocodiles that were seen but not caught were recorded, with a size estimate when possible. These data are used to validate our 2009 spotlight survey by providing repeated surveys of the same sections of river, and to estimate the sex ratio of the population from captured animals.

\section{Analysis}

Google Earth v. 5.2.1 (Googleplex, California, USA) and ArcGIS v. 9.3.1 (ESRI, Redlands, USA) were used for mapping and measurement of the riverbank frontage. This included the main riverbanks of Zambia and Zimbabwe as well as the perimeter of all islands. Statistical analyses were performed using $R$ v. 2.10.1 (R Development Core Team, 2008). Linear regression was used to investigate correlation between levels of protection/habitation and crocodile density. The areas were assigned values $0,1,2$ or 3 , representing no, low, medium and high wildlife/habitat protection (corresponding to high levels of human habitation through to no permanent human habitation). The values for each area were: o, Siavunga Open Area; 1, Kafue River; 2, Chiawa and Rufunsa Game Management Areas; 3, Hurungwe, Sapi and Chewore Safari Areas, Lower Zambezi National Park and Mana Pools. The values were used as explanatory variables for crocodile density per $\mathrm{km}$. As spotlight surveys are renowned for underestimating 
populations linear regression was used to investigate correlations between the maximum number of crocodile sightings in the sections (using 6-20 repeated surveys) and the number of crocodiles seen during the 2009 spotlight survey for that same section. As the spotlight data consisted of count data, comparisons of crocodile population structure between areas, surveys and the matrix model were made using contingency tables.

\section{Matrix model parameterization}

The Nile crocodile life cycle was separated into four ontogenetic categories (following those of Fergusson's survey in 2006) to estimate stage class for the matrix model. Stage 1 represents the first year, when hatchlings enter a phase of high predation (hatchlings and yearlings, see above). Stage 2 represents the immature juvenile stage (juveniles) lasting 2 years, when the animals enter a period of reduced predation. Stage 3 represents the immature to early mature subadult stage (subadults) lasting 19 years. Stage 4 represents the adult age class (adults), when individuals enter the main reproductive portion of the population, lasting c. 28 years, completing the presumed 50-year life cycle in the wild. The survivorship values are distributed between the potential of an animal surviving and moving from one stage to the next (Gi) or surviving and remaining in the same stage $(P i)$. Here we use the duration of each stage $(d j)$ and overall stage-specific survivorship $(P i)$ following methods of Caswell (2001):

The transition matrix for the stage classification is:

$$
\begin{aligned}
& A=\left(\begin{array}{llll}
0 & 0 & F 3 & F 4 \\
G 1 & P 2 & 0 & 0 \\
0 & G 2 & P 3 & 0 \\
0 & 0 & G 3 & P 4
\end{array}\right) \\
& G i=\left(\frac{P i^{d j}(1-P i)}{1-P i^{d j}}\right) \\
& P i=\left(\frac{1-P i^{\mathrm{d} j-1}}{1-P i^{\mathrm{d} j}}\right) P i \\
& F 4=(P F)(E P C)(N E)(P R)(\varphi) \\
& F 3=\text { (duration subadult is reproductive) } \\
& \text { total years subadult) } F 4 \\
& A=\left(\begin{array}{llll}
0 & 0 & 1.5 & 7.2 \\
0.12 & 0.32 & 0 & 0 \\
0 & 0.15 & 0.94 & 0 \\
0 & 0 & 0.04 & 0.95
\end{array}\right)
\end{aligned}
$$

Demographic parameters for the matrix were obtained from existing literature (Supplementary Table $S_{1}$ ). Adult reproductive rate $\left(F_{4}\right)$ depended on $P F$, the proportion of females in the population (0.54); EPC, mean eggs per clutch (45.48); $N E$, nest effort or proportion of reproductively active females that breed and nest (0.66); $P R$, proportion of eggs depredated (0.45); and $\varphi$, survivorship of adults (0.98). The minimum size of a female breeding Nile crocodile is c. $2.3 \mathrm{~m}$ total length at c. 15 years of age, which falls within the later part of the subadult stage. To maintain consistency with the 2006 survey the subadult reproductive rate $\left(F_{3}\right)$ was calculated as the proportion of time reproductively active (total length 2.3-2.5 $\mathrm{m}$, the last 4 years of the subadult class) as a function of $F_{4}$. Growth rates were derived by combining growth data across male and female C. niloticus (Hutton, 1984; Games, 1990) and survivorship values estimated from a study by Bourquin (2007). Sensitivities and elasticities were calculated, as was the stable age distribution and population growth rate $(\lambda)$.

\section{Results}

\section{Spotlight survey}

A total of 1,761 crocodiles were encountered during the spotlight survey in 2009 , a third $(33.8 \%, \mathrm{n}=595)$ were classed as eyes-only sightings. The size class structure was skewed towards the smaller size classes $\left(\chi^{2}=194.7, \mathrm{P}<0.01\right.$, $\mathrm{df}=2), 51.5 \%$ were juveniles $(\mathrm{n}=601), 29.7 \%$ subadult $(\mathrm{n}=346)$ and $18.8 \%$ adult. During the capture surveys a total of 505 individual crocodiles were caught; $\mathrm{n}=79(15.7 \%)$ yearlings; $\mathrm{n}=311(61.6 \%)$ juveniles; $\mathrm{n}=112(22.2 \%)$ subadults; $n=4(0.6 \%)$ adults. The overall sex ratio of captured individuals was $52.8 \%$ male to $47.2 \%$ female. There was a strong correlation between the number of crocodiles sighted during the spotlight survey and the maximum number sighted for that particular section during the repeated area surveys $\left(\mathrm{r}^{2}=0.93 \mathrm{P}<0.01, \mathrm{df}=6\right)$. Overall the spotlight survey recorded $0.84 \pm \mathrm{SE} 0.05$ of the maximum number of crocodiles seen in the same areas as determined by the capture surveys.

Assuming random and non-selective spotting and catching, both surveys (spotlight and capture) would be expected to show similarities in the percentages of size classes seen. However, there were differences between the overall percentages of the size classes identified in the spotlight survey and the capture surveys $\left(\chi^{2}=235.3\right.$, $\mathrm{P}<0.01, \mathrm{df}=3)$. The spotlight survey recorded more adults (12.4\%) than the capture surveys $(7.7 \%)$ and fewer subadults (19.6 and 30.1\%, respectively). The two surveys recorded similar juvenile (34.1 and 31.1\%, respectively) and eyes-only sightings (33.8 and $31.2 \%$, respectively).

The crocodiles were not equally distributed throughout the study site, with considerable variation in encounter rates for the different areas (Table 1). Crocodile density increased in areas with higher protection $\left(\mathrm{r}^{2}=0.79, \mathrm{P}=0.01, \mathrm{df}=7\right)$, from Siavunga Open Area $\left(0.9 \mathrm{~km}^{-1}\right)$ to Mana Pools $\left(5.4 \mathrm{~km}^{-1}\right)$. 
TABLE 1 Demographics of Nile crocodile Crocodylus niloticus in the lower Zambezi valley (Fig. 1), estimated from a spotlight survey in 2009. Protection is an estimate of wildlife/habitat protection (see text for details). Riverbank is the main shoreline and does not include islands because of the difficulty in determining if they are Zambian or Zimbabwean.

\begin{tabular}{|c|c|c|c|c|c|c|c|c|}
\hline Region (by country) & Protection & $\begin{array}{l}\% \\
\text { juveniles }\end{array}$ & $\begin{array}{l}\% \\
\text { subadults }\end{array}$ & $\begin{array}{l}\% \\
\text { adults }\end{array}$ & $\begin{array}{l}\% \\
\text { eyes-only }\end{array}$ & $\begin{array}{l}\text { No. of } \\
\text { crocodiles seen }\end{array}$ & $\begin{array}{l}\text { River bank } \\
\text { length }(\mathrm{km})\end{array}$ & $\begin{array}{l}\text { Crocodile } \\
\text { density }\left(\mathrm{km}^{-1}\right)\end{array}$ \\
\hline \multicolumn{9}{|l|}{ Zambia } \\
\hline Siavunga Open Area & None & 54.7 & 15.1 & 5.7 & 24.5 & 53 & 56 & 0.9 \\
\hline $\begin{array}{l}\text { Chiawa Game Management } \\
\text { Area }\end{array}$ & Moderate & 56.8 & 14.2 & 8.0 & 21.0 & 162 & 58 & 2.8 \\
\hline Lower Zambezi National Park & High & 32.8 & 9.6 & 25.5 & 32.2 & 491 & 107 & 4.6 \\
\hline $\begin{array}{l}\text { Rufunsa Game Management } \\
\text { Area }\end{array}$ & Moderate & 66.7 & 8.3 & 8.3 & 16.7 & 36 & 30 & 1.2 \\
\hline Kafue River & Low & 61.0 & 16.9 & 8.5 & 13.6 & 59 & 40 & 1.5 \\
\hline \multicolumn{9}{|l|}{ Zimbabwe } \\
\hline Hurungwe Safari Area & High & 40.3 & 15.1 & 9.7 & 34.9 & 186 & 80 & 2.4 \\
\hline Mana Pools & High & 12.2 & 12.5 & 27.5 & 47.9 & 353 & 66 & 5.4 \\
\hline Sapi Safari Area & High & 46.8 & 8.2 & 5.7 & 39.2 & 158 & 33 & 4.8 \\
\hline Chewore Safari Area & High & 44.5 & 20.9 & 4.2 & 30.4 & 263 & 74 & 3.6 \\
\hline Total & & 13.1 & 16.1 & 33.8 & 37.0 & 1,761 & 544 & 3.2 \\
\hline
\end{tabular}

TABLE 2 Percentage of C. niloticus size classes (including unclassified eyes-only sightings) in the lower Zambezi River in 2006 (from Fergusson, 2006) and 2009. The size structure of the sections is compared using $\chi^{2}$ contingency tables. The western section is the area between Ruckomechi and Nyamumba ( $263 \mathrm{~km}$ of riverbank); the eastern section is from Kanyemba to Ruckomechi (504 km of riverbank).

\begin{tabular}{|c|c|c|c|c|c|c|c|c|c|}
\hline \multirow[b]{2}{*}{ Year } & \multirow[b]{2}{*}{ Section } & \multicolumn{4}{|c|}{ Size category (\%) } & \multirow{2}{*}{$\begin{array}{l}\text { No. of } \\
\text { crocodiles seen }\end{array}$} & \multirow[b]{2}{*}{$\chi^{2}$} & \multirow[b]{2}{*}{$\mathrm{df}$} & \multirow[b]{2}{*}{$\mathrm{P}$} \\
\hline & & Juveniles & Subadults & Adults & Eyes-only & & & & \\
\hline \multirow[t]{2}{*}{2006} & Western & 47.6 & 8.1 & 2.8 & 41.5 & 246 & 15.7 & 3 & $<0.01$ \\
\hline & Eastern & 22.8 & 8.5 & 16.7 & 52.0 & 1,124 & & & \\
\hline \multirow[t]{2}{*}{2009} & Western & 38.2 & 22.3 & 6.6 & 32.9 & 319 & 77.3 & 3 & $<0.01$ \\
\hline & Eastern & 32.3 & 18.9 & 14.0 & 34.9 & 1,383 & & & \\
\hline
\end{tabular}

The population structure of the two main river sections differed in both the 2006 and the 2009 surveys (Table 2). The overall percentage of crocodiles sighted (including eyesonly) in the eastern section in 2006 and 2009 were similar (81.3 and $81.5 \%$, respectively), and also in the western section (18.7 and $18.5 \%$, respectively). The 2009 measurements of riverbank indicate that the eastern section was twice the length $(67 \%)$ of the western section (33\%). The approachability of crocodiles did not differ greatly between the eastern and western areas during 2006 (eyes-only sightings 50.4 and $41.3 \%$ respectively) and 2009 (34.9 and $32.9 \%)$.

Crocodile density differed between the 2006 and 2009 surveys because of a disparity in bank length measurements for the same sections. The eastern section was measured as $268.9 \mathrm{~km}$ in 2006 and $599.0 \mathrm{~km}$ in 2009 , the western section as 207.5 and $295.0 \mathrm{~km}$ respectively. This is a large disparity and we are confident that the 2009 measurements are accurate. It is doubtful that bank erosion would have caused such a change. The 2009 measurements follow the contours of the banks on either side of the River. We surmise, therefore, that the 2006 measurements are of the route of the boat between sightings. For the purpose of comparison the 2006 population estimate was corrected with the 2009 riverbank measurements. There was an overall increase in density from $2.2 \mathrm{~km}^{-1}$ in 2006 to $2.5 \mathrm{~km}^{-1}$ in 2009 . The eastern section had a slight increase from 3.0 to $3.1 \mathrm{~km}^{-1}$ and the western section 0.6 to $1.4 \mathrm{~km}^{-1}$. The final corrected population estimate (Table 3 ) in 2009 was c. 2,257 crocodiles, The 2006 estimate was c. 1,984. Over the 3 years there was a larger increase in the number of crocodiles in the western $(29.7 \%)$ than in the eastern section $(23.0 \%)$.

\section{Matrix model}

The population size structure of the crocodiles recorded in both the 2006 and 2009 surveys differed from that predicted by the matrix model. A much lower percentage of juveniles and a higher percentage of subadults were estimated by the matrix than was seen on either spotlight survey throughout the entire study site or in the western and eastern sections separately (Fig. 2). To achieve the observed population structure it was necessary to perturb the matrix parameters to a substantial (and unrealistic) extent by reducing subadult 
TABLE 3 Population estimates of C. niloticus on the lower Zambezi River based on a spotlight survey. Riverbank is the actual shoreline of the mainland and islands. Unsurveyed riverbank $(\mathrm{km})$ is the distance not covered by the survey because of inaccessibility. This was derived by comparing the GPS route to an image of the study area, in ArcGIS. Correction for riverbank is the percentage of riverbank omitted during the survey. Correction for survey was estimated using data of repeated surveys of the same sections.

\begin{tabular}{llll}
\hline & $\begin{array}{l}\text { Western } \\
\text { section }\end{array}$ & $\begin{array}{l}\text { Eastern } \\
\text { section }\end{array}$ & Overall \\
\hline Riverbank $(\mathrm{km})$ & 263 & 504 & 767 \\
Absolute numbers seen & 319 & 1,383 & 1,702 \\
Sightings classified & $67.1 \%$ & $65.1 \%$ & $65.5 \%$ \\
Unsurveyed riverbank $(\mathrm{km})$ & 32 & 95 & 127 \\
Correction for riverbank & $+12.2 \%$ & $+18.8 \%$ & $+16.6 \%$ \\
Correction for survey & $+16.0 \%$ & $+16.0 \%$ & $+16.0 \%$ \\
Corrected total no. of crocodiles & 409 & 1,864 & 2,257 \\
Corrected crocodiles $\mathrm{km}^{-1}$ & 3.7 & 1.2 & 2.2 \\
\hline
\end{tabular}

survivorship to $0.60(\lambda=0.97)$. Increasing juvenile survival to represent a higher percentage of that stage class in turn increased the larger size classes. The unperturbed matrix predicted a population growth rate of c. $5 \%$ per year, which is feasible given the observed population growth rate between the 2006 and 2009 spotlight survey estimates. The reproductive values increased with body size: yearling $0.8 \%$, juvenile $6.9 \%$, subadult $33.3 \%$ and adult $59.0 \%$. The predicted stable stage structure was $66.9 \%$ yearling, $11.1 \%$ juvenile, $15.6 \%$ subadult and $6.5 \%$ adult. When the yearling percentage is omitted the stage structure became $33.4 \%$ juvenile, $47.1 \%$ subadult and $19.5 \%$ adult. The elements in the sensitivity matrix (Table 4) indicate that growth from the subadult to the adult stage has the highest sensitivity (o.89), with subadult persistence (0.45) and probability of growing (0.34) and remaining an adult (0.34) exhibiting the highest elasticities. Expected number of replacements was 3.2 per individual and the mean age of a reproductively active female was 35.0 years.

\section{Discussion}

The lower Zambezi crocodile population size reported here is a minimum estimate. Spotlight surveys tend to underestimate actual densities (Hutton \& Woolhouse, 1989). The use of correction factors is an attempt to estimate the actual population size given the biases involved with the survey technique. Nonetheless it appears that the lower Zambezi crocodile population increased between 2006 and 2009. The observed and predicted $\lambda$ are close yet the observed population structure differs from that expected in the matrix model given the demographic rates published in the literature (Craig et al., 1992; Tucker, 2001).

Despite the biases of spotlight surveys our results provide a useful estimate of the crocodile population. A survey with

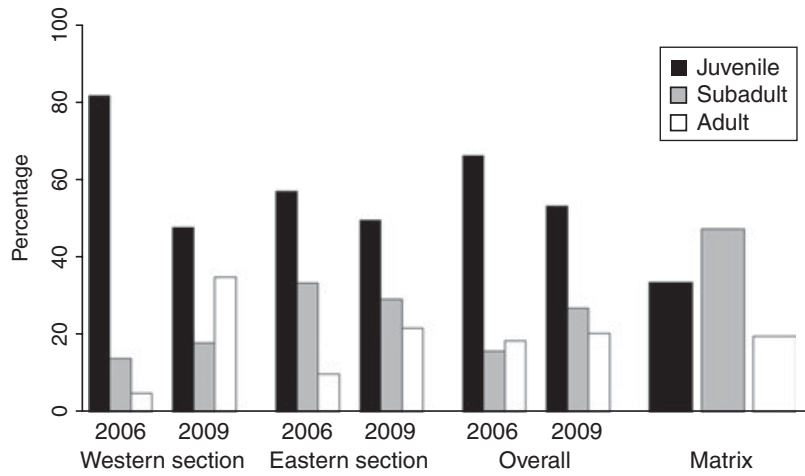

FIG. 2 Size structure of Crocodylus niloticus determined from spotlight survey counts during September 2006 (Fergusson 2006) and 2009 (this survey), overall (western and eastern sections combined) and from a stage-based matrix model.

two boats (one for each bank) would have been ideal but logistical problems precluded this. We assume there is no bias because of crocodiles crossing the river between Zambia and Zimbabwe as each crossing could be countered by another in the opposite direction.

The same densities of crocodiles were sighted in the two sections of the Zambezi in both spotlight surveys. Crocodile density was highest in the eastern section, which is characterized by increased wildlife/habitat protection. This demonstrates the positive influence of protected areas for conservation of this crocodile. However, the rate of population increase was lower in the eastern section than the western section. There is a possibility of densitydependent factors controlling population growth, which has been described in other studies (Velasco et al., 2003).

A deterministic matrix predicts that a population converges to a stable stage distribution. In the wild populations are not deterministic but a population fluctuating around equilibrium may nevertheless have a structure close to that predicted by a deterministic model. The large disparity between prediction and observation suggests either a problem with the model, a population a long way from equilibrium, or bias in the data (such as with the eyesonly data). The latter constitutes a substantial proportion of the sightings yet cannot be included within the size classifications unless further assumptions are made; e.g. that they are all adult crocodiles.

The size class structure in the eastern section was similar in 2006 and 2009. The largest disparities are in the western section. The large proportion of eyes-only sightings in both surveys makes it difficult to draw accurate conclusions, however. The size and therefore the size class allocations of a third of sightings were not obtained and so it is difficult to categorize these animals. It is possible that these are the larger, more wary animals. Previous studies have indicated that recapture probabilities decrease with increasing crocodile size (Bourquin, 2007) because of human disturbance, including from capture and release techniques 
TABLE 4 Sensitivity and elasticity values for $C$. niloticus matrix elements. The matrix notation indicates values for an animal surviving and remaining in the same stage $(\mathrm{Gi})$; surviving and moving from one stage to the next $(\mathrm{Pi})$; and reproductive rate (Fi) for yearling (1), juvenile (2), subadult (3) and adult (4) size classes.

\begin{tabular}{|c|c|c|c|c|c|c|c|c|c|c|c|c|}
\hline & \multicolumn{4}{|c|}{ Matrix } & \multicolumn{4}{|c|}{ Sensitivity } & \multicolumn{4}{|c|}{ Elasticity } \\
\hline & 1 & 2 & 3 & 4 & 1 & 2 & 3 & 4 & 1 & 2 & 3 & 4 \\
\hline 1 & & & $F 3$ & $F 4$ & & & 0.01 & 0.00 & & & 0.02 & 0.03 \\
\hline 2 & $G 1$ & $P 2$ & & & 0.45 & 0.07 & & & 0.05 & 0.02 & & \\
\hline 3 & & G2 & $P 3$ & & & 0.36 & 0.50 & & & 0.05 & 0.45 & \\
\hline 4 & & & G3 & $P 4$ & & & 0.89 & 0.37 & & & 0.03 & 0.34 \\
\hline
\end{tabular}

(Ron et al., 1998). The western section is the most exploited part of the lower Zambezi study site for crocodile ranching and hunting (regulated by the wildlife departments of Zambia and Zimbabwe). Although exploitation does occur in the Zambia Rufunsa Game Management Area as well as the Zimbabwe safari areas, the overall level of protection for the eastern section is higher. Crocodile ranching quotas usually stipulate the number of eggs and breeding adults (mainly females), and trophy hunting includes the larger animals. Data on the actual offtake and locations are unavailable but would shed light on the difference between the population age classes. The observed disparities could also be because of other forms of disturbance to the population, including habitat issues. The Chiawa Game Management Area (part of the western section) has an increasing human population and agricultural activities. This could reduce available basking and nesting areas and increase harassment by humans.

The lower Zambezi includes areas allocated for crocodile ranchers to collect live adults. The western section has the greatest proportion of this harvesting, which uses the same spotlight technique as our research team. It could be surmised that the crocodiles in the western area were subject to a higher effort of capture for harvest or research. However, this did not appear to affect the wariness of crocodiles as the ratio of sightings to eyes-only (possibly more wary crocodiles) were similar for the western and eastern sections. Although eyes-only sightings were highest in the eastern area this may have been because of physical limitations rather than crocodile wariness. Navigation in the eastern section was more difficult (especially in the Lower Zambezi National Park and Mana Pools) because of shallows, sand bars, submerged obstacles and a higher density of potentially dangerous animals such as the hippopotamus Hippopotamus amphibius.

If we assume that the size structure estimates are accurate and that the population is not subject to duress then the observations would show a trend towards the stable stage structure predicted by the matrix. This would require a reduction in the number of individuals in the juvenile size class, increase in the subadult class and reduction in the adult class. This pattern can be seen in a comparison of the results of the 2006 survey with our 2009 survey.
The population thus appears to be drifting towards the theoretical stable stage structure. When comparing the western and eastern sections the difference in relation to the matrix prediction is apparent. The eastern section is more similar to the prediction than the western, which is characterized by a large proportion of smaller crocodiles. This could be explained by an offtake of larger individuals, skewing the size structure towards the smaller size classes. It is not known if this population has suffered a major perturbation in the past. However, the area is subject to harvesting of crocodile eggs and adults, sanctioned by the Zambian Wildlife Authority, and it is therefore difficult to estimate how many years the population would require to reach an equilibrium given the population structure in 2006.

A high sensitivity value indicates that an independent change in that matrix element could cause a considerable change in the expected population growth rate. This was found to occur in the transition phase from subadult to adult at c. $2.5 \mathrm{~m}$ total length (c. 22 years). This size of animal would be desirable for crocodile farming: small enough to capture, at reproductive prime and with enough expected remaining life expectancy to adjust to captivity. This suggests that the targeted animals are within the class that has the greatest potential to affect the population. Elasticity predicts the proportional change in the growth rate given a proportional change in the matrix element, while all other elements remain constant. The highest elasticity values are remaining in the subadult and adult stage. This finding concurs with models that predict that the harvesting of larger individuals, especially those at sexual maturity, will have a disproportionately large effect on the rate of change of the population (Enneson \& Litzgus, 2008). The sensitivity and elasticity values are lowest for the fecundity rate and the earlier life history stages. This concurs with current management strategies that removal of eggs and hatchlings from the wild will have the least effect on the growth rate of the wild population. Elasticity values are useful for formulation of conservation plans but need to be interpreted with considerable care (Mills et al., 1999) because they assume the effects of perturbing a demographic rate is linear, and the model assumes no density dependence or environmental stochasticity. Typically, matrix elements 
with high elasticity values are targeted by management plans as a high priority, with less emphasis placed on those elements that have low rates. In density-dependent models a perturbation to one element will in turn affect all other matrix elements. Results of perturbations in the natural system can differ substantially from predictions. In addition, certain age/stage classes may be more or less susceptible to conservation measures and may react unpredictably. The matrix represents a deterministic theoretical population and in the natural environment there are many factors that can influence the population but have not been included in this simulation. Factors such as temperature-dependent sex determination, density dependence, prey abundance and nest site availability could all influence population demography. Despite this, the matrix does offer an opportunity to examine whether the Zambezi population conforms to our general understanding of crocodilian life histories.

Our results indicate an increasing crocodile population that is still far from equilibrium. Future surveys are required to validate this trend. The importance of protected areas is clearly illustrated yet there is evidence that the population is increasing at a faster rate in areas that have a lower density of crocodiles. It is important to monitor the patterns of land-use change, especially in the game management and open areas, as loss of habitat has been cited as one of the main causes of crocodile population decline. Additional information regarding the harvesting and hunting of animals is required, as identifying this offtake (specimen size as well as numbers) will assist with the monitoring and management of the population. Our findings will be passed to the appropriate authorities (government and NGOs) that are involved with the management of crocodiles in Zambia and Zimbabwe. There has been no active crocodile research in this area since 2009 but we recommend repeating the survey at intervals of 3 years, to maintain population monitoring. Any future project could usefully involve the local crocodile farming industry as they also have an interest in maintaining a viable crocodile population.

\section{Acknowledgements}

We wish to acknowledge the Zambian Wildlife Authority (ZAWA) and Zimbabwe Parks and Wildlife Management Authority (ZPWMA) for their assistance. Research permits were obtained from ZAWA and ZPWMA and the study complied with all appropriate ethics, guidelines and regulations. The research protocols were approved by the Ethical Review Process of Imperial College London, UK. We thank Kerri Radmeyer, Adrian Hudson and the staff at Conservation Lower Zambezi for logistical assistance, Pete, Debbie, Steve Vrdoljak and staff at Wildtracks as well as Reginald Mfula and staff at Kwalata Lodge for accommodation and support, the lodges and people of the Lower
Zambezi who assisted the project (Zambezi Breezers Lodge, Kanyemba Lodge, Chongwe River Camp, Sausage Tree Camp, Kulefu Camp, Mwambashi River Lodge, Anna Tree Lodge, and Andrew and Julie Woodley of Fringila), and Davie and Ardri Visser at Baya Baya farm. Financial support was provided by the Earthwatch Institute and the National Environment Research Council, UK.

\section{References}

Ballouard, J.M., Priol, P., Oison, J., Ciliberti, A. \& Cadi, A. (2010) Does reintroduction stabilize the population of the critically endangered gharial (Gavialis gangeticus, Gavialidae) in Chitwan National Park, Nepal? Aquatic Conservation: Marine and Freshwater Ecosystems, 20, 756-761.

Bayliss, P., Webb, G.J.W., Whitehead, P.J., Dempsey, K. \& Sмith, A. (1986) Estimating the abundance of saltwater crocodiles, Crocodylus porosus Schneider, in tidal wetlands of the Northern Territory-a mark-recapture experiment to correct spotlight counts to absolute numbers, and the calibration of helicopter and spotlight counts. Australian Wildife Research, 13, 309-320.

Bishop, J.M., Leslie, A.J., Bourquin, S.L. \& O’Ryan, C. (2009) Reduced effective population size in an overexploited population of the Nile crocodile (Crocodylus niloticus). Biological Conservation, 142, 2335-2341.

Bourquin, S.L. (2007) The population ecology of the Nile crocodile (Crocodylus niloticus) in the Panhandle region of the Okavango Delta, Botswana. PhD thesis. University of Stellenbosch, Stellenbosch, South Africa.

Caswell, H. (2001) Matrix Population Models: Construction, Analysis, and Interpretation. Sinauer Associates, Sunderland, USA.

Cherkiss, M.S., Mazzotti, F.J. \& Rice, K.G. (2006) Effects of shoreline vegetation on visibility of American crocodiles (Crocodylus acutus) during spotlight surveys. Herpetological Review, 37, 37-40.

Craig, G.C., Gibson, D.S.C. \& Hutton, J.M. (1992) A population model from the Nile crocodile and simulation of different harvesting. In The CITES Nile Crocodile Project (eds J.M. Hutton \& I. Games), pp. 1-52. CITES Secretariat, Lausanne, Switzerland.

Crocodile Specialist Group (1996) Crocodylus niloticus. In IUCN Red List of Threatened Species v. 2012.1. Http://www.iucnredlist.org [accessed 27 September 2012].

Detoeuf-Boulade, A.S. (2006) Reproductive Cycle and Sexual Size Dimorphism of the Nile Crocodile (Crocodylus niloticus) in the Okavango Delta, Botswana. MSc thesis. University of Stellenbosch, Stellenbosch, South Africa.

EnNeson, J.J. \& LitzGus, J.D. (2008) Using long-term data and a stage-classified matrix to assess conservation strategies for an endangered turtle (Clemmys guttata). Biological Conservation, $141,1560-1568$.

Fergusson, R. (2006) Populations of Nile crocodile (Crocodylus niloticus) and hippopotamus (Hippopotamus amphibius) in the Zambezi. African Wildlife Foundation, Zambezi Heartland.

Gallegos, A., Plummer, T., Uminsky, D., Vega, C., Wickman, C. \& ZAWoISKI, M. (2008) A mathematical model of a crocodilian population using delay-differential equations. Journal of Mathematical Biology, 57, 737-754.

Games, I. (1990) The feeding ecology of two Nile crocodile populations in the Zambezi Valley. PhD thesis. University of Zimbabwe, Harare. Graham, A. (1968) The Lake Rudolf Crocodile (Crocodylus niloticus Laurenti) Population. A Report to the Kenya Game Department by Wildlife Services Ltd. Kenya Game Commission, Nairobi, Kenya. 
Hartley, D.D.R. (1990) A survey of crocodile nests in Umfolozi Game Reserve. The Lammergeyer, 41, 1-12.

Hutton, J.M. (1984) Population Ecology of the Nile crocodile, Crocodylus niloticus, Laurenti 1768, at Ngezi, Zimbabwe. $\mathrm{PhD}$ thesis. University of Harare, Harare, Zimbabwe.

Hutton, J.M. (1987) Morphometrics and field estimation of the size of the Nile crocodile. African Journal of Ecology, 25, 225-230.

Hutton, J.M. \& Woolhouse, M.E.J. (1989) Mark recapture to assess factors affecting the proportion of a Nile crocodile population seen during spotlight counts at Ngezi, Zimbabwe, and the use of spotlight counts to monitor crocodile abundance. Journal of Applied Ecology, $26,381-395$.

Hutton, J.M., Ross, J.P. \& Weвb, G. (2002) Using the market to create incentives for the conservation of crocodilians: a review. In Crocodiles: Proceedings of the 16th Working Meeting of the IUCN/ SSC Crocodile Specialist Group, pp. 382-399. IUCN, Gland, Switzerland.

Kofron, C.P. (1989) Nesting ecology of the Nile crocodile (Crocodylus niloticus). African Journal of Ecology, 27, 335-341.

Kofron, C.P. (1990) The reproductive cycle of the Nile crocodile (Crocodylus niloticus). Journal of Zoology, 221, 477-488.

LAINEZ, D. (2008) Fifty years of crocodile surveys in Africa: a review of the surveys and population trends. MSc thesis. University College London, London, UK.

Maciejewski, K. (2006) Temperature-dependent sex determination in the Nile crocodile Crocodylus niloticus in the Okavango River, Botswana, and the effect of global climate change. MSc thesis. University of Stellenbosch, Stellenbosch, South Africa.

Mazzotti, F.J., Best, G.R., Brandt, L.A., Cherkiss, M.S. Jeffery, B.M. \& Rice, K.G. (2009) Alligators and crocodiles as indicators for restoration of Everglades ecosystems. Ecological Indicators, 9, $\mathrm{S}_{137}-\mathrm{S}_{149}$.

McGregor, J. (2005) Crocodile crimes: people vs wildlife and the politics of postcolonial conservation on Lake Kariba, Zimbabwe. Geoforum, 36, 353-369.

Mills, L.S., Doak, D.F. \& Wisdom, M.J. (1999) Reliability of conservation actions based on elasticity analysis of matrix models. Conservation Biology, 13, 815-829.

Parker, I. \& Watson, R. (1970) Crocodile distribution and status in the major waters of western and central Uganda in 1969. East African Wildlife Journal, 8, 85-69.

Pooley, A.C. (1969) Preliminary studies on the breeding of the Nile crocodile Crocodylus niloticus, in Zululand. The Lammergeyer, $10,22-44$.

R Development Core team (2008) R: A Language and Environment for Statistical Computing. R Foundation for Statistical Computing, Vienna, Austria. Http://www.R-project.org [accessed 19 April 2013].

Ron, S.R., Vallejo, A. \& Asanza, E. (1998) Human influence on the wariness of Melanosuchus niger and Caiman crocodilus in Cuyabeno, Ecuador. Journal of Herpetology, 32, 320-324.
Seijas, A.E. \& Chavez, C. (2000) Population status of the Orinoco crocodile (Crocodylus intermedius) in the Cojedes river system, Venezuela. Biological Conservation, 94, 353-361.

Siamudaala, V.M., Kunda, C. \& Nambota, A.N. (2004) The Nile crocodile (Crocodylus niloticus) farming industry in Zambia. Game \& Wildlife Science, 21, 853-863.

Sмiтн, A.M.A. \& Weвв, G.J.W. (1985) Crocodylus johnstoni in the Mckinlay River area, N.T. VIII. A population simulation model. Australian Wildlife Research, 12, 541-554.

Swanepoel, D.G.J., Ferguson, N.S. \& Perrin, M.R. (2000) Nesting ecology of Nile crocodiles (Crocodylus niloticus) in the Olifants River, Kruger National Park. Koedoe, 43, $35-46$.

Telleria, J.L., Ghaillani, H.E.M., Fernandez-Palacios, J.M., Bartolome, J. \& Montiano, E. (2008) Crocodiles Crocodylus niloticus as a focal species for conserving water resources in Mauritanian Sahara. Oryx, 42, 292-295.

Thorbjarnarson, J.B. (1996) Reproductive characteristics of the order Crocodylia. Herpetologica, 52, 8-24.

Thorbjarnarson, J.B., Wang, X.M., Ming, S., He, L.J., Ding, Y.Z., Wu, Y.L. \& McMurry, S.T. (2002) Wild Populations of the Chinese alligator approach extinction. Biological Conservation, 103, 93-102.

Tucker, A.D. (2001) Sensitivity Analysis of Stage-structured Demographic Models for Freshwater Crocodiles. Surrey Beatty \& Sons, Chipping Norton, Australia.

Velasco, A., Colomine, G., De Sola, R. \& Villarroel, G. (2003) Effects of sustained harvests on wild populations of Caiman Crocodilus crocodilus in Venezuela. Interciencia, 28, 544-548.

Webi, G.J.W. \& Messel, H. (1977) Crocodile capture techniques. Journal of Wildlife Management, 41, 572-575.

Webb, G.J.W., Britton, A., Manolis, C., Ottley, B. \& Stirrat, S. (2000) Recovery of saltwater crocodiles (C. porosus) in the Northern Territory of Australia: 1971-1998. In Crocodiles: Proceedings of the 15th Working Meeting of the Crocodile Specialist Group, pp. 195-234. IUCN, Gland, Switzerland.

\section{Biographical sketches}

Kevin M. Wallace and Audrey S. Wallace have been involved with crocodile research for 7 years. Kevin has a wide interest in ecology and wildlife conservation management. ALISON LESLIE's research interests are wildlife ecology, vertebrate physiology and aquatic conservation. She is particularly interested in the ecology and conservation of crocodiles and sea turtles. Tim CouLson's research concentrates on how demographic rates vary across groups of individuals and environments, and the ecological and evolutionary consequences of this variation. 